\title{
HEAT EXCHANGE AND CHARGING OF A METALLIC PARTICLE SURROUNDED BY CONDENSED DISPERSED PHASE OF ITS OXIDE
}

\author{
O.S. CHERNENKO, K.I. SEMENOV, L.A. LYALIN, V.V. KALINCHAK, \\ O.V. MANDEL
}

PACS 82.70.-y, 44.35.+c (C) 2011
I.I. Mechnikov Odessa National University

(2, Dvoryanskaya Str., Odessa, Ukraine; e-mail: semenovki@ te. net.ua)
The time of setting of a stationary charge of particles of copper and tantalum, heated up to the melting temperature due to the electric exchange with a condensed dispersion phase of its own oxide, is determined. It is also shown that, for every time moment, the falling metallic particle can be considered as the one having a quasistationary electric charge, due to the non-stationary heat exchange with the surrounding. Experimental data on the charge of copper particles and its cooling characteristics are presented.

The charge of spherical particles of copper $(\mathrm{Cu})$ and tantalum (Ta), surrounded by a condensed dispersed phase (CDP) of their oxides $\left(\mathrm{Cu}_{2} \mathrm{O}\right.$ and $\left.\mathrm{Ta}_{2} \mathrm{O}_{5}\right)$, was experimentally researched in [1]. Spherical particles of copper and tantalum were manufactured in air at normal temperature (about $300 \mathrm{~K}$ ) from the copper and tantalum wires, which were inserted in the pre-set regime into an arch generator [2]. As a result, the manufactured particles were heated up to the temperatures above the melting points of copper and tantalum, being surrounded by the CDP zone of copper protoxide at the temperature $T_{f}=2073 \mathrm{~K}$ or tantalum protoxide at the temperature $T_{f}=1743 \mathrm{~K}$.

When the metallic particle and the CDP exchange by electric charges, the particle gets a non-compensated positive or negative charge [3]. A timing of this process was analytically estimated in [2]. The equation of charging of a particle is

$$
\frac{d q}{d t}=4 \pi r_{s}^{2}\left(j_{s}-j_{f}\right)
$$

The flux density of electrons from the surface of a heated particle at the thermoelectronic emission is defined by the Richardson-Dushman equation $j_{s}=$ $B T^{2} \exp \left(-\frac{A-\Delta A}{k T}\right)$ where $B=B_{0} F(q), F(q)=1-\bar{R}_{e}$, $B_{0}=1.2 \times 10^{6} \mathrm{~A} / \mathrm{m}^{2}$ is the universal constant, $\bar{R}_{e}$ is the coefficient of reflection of electrons from the nitrogen atoms, a process that returns some electrons back to a particle, $A$ - work of electron's exit from a particle, and $\Delta A-$ change of this work due to the charge being present on a particle. For a negatively charged particle, the work of electron's exit decreases, for a positively charged particle it increases:

$$
\Delta A= \begin{cases}|q|^{1 / 2} e^{3 / 2} / 4 \pi \varepsilon_{0} r, & \text { if } q<0 \\ -q e / 4 \pi \varepsilon_{0} r, & \text { if } q>0\end{cases}
$$

The flux density of negative oxygen ions from CDP onto the particle is determined by the process of thermoelectronic emission of electrons from CDP [1]:

$j_{f}=B_{0} T_{f}^{2}\left[1-\frac{\Psi(q)}{\bar{v}_{\mathrm{O}_{2}}}\right] \exp \left(-\frac{A_{f}}{k T_{f}}\right)$,

where $T_{f}$ - temperature of CDP, $A_{f}$ - work of electron's exit from CDP particles, $\bar{v}_{\mathrm{O}_{2}}$ - average speed of motion of oxygen ions, $\Psi(q)$ - function that considers the breaking of the flux of oxygen ions in the kinetic zone that is equal to

$\Psi(q)=\left\{\begin{array}{l}0, \quad \text { if } q<0,0<|q| \leq\left(e r^{2} / 4 \ell^{2}\right) \\ \left(e L_{1} \bar{v}_{\mathrm{O}_{2}} / 4 \pi \varepsilon_{0} r^{2} k T_{f}\right) \times \\ \times\left(|q|^{1 / 2}-r e^{1 / 2} / 2 \ell\right)^{2} \\ \text { if } q<0,|q|>\frac{e r^{2}}{4 \ell^{2}} \\ 0, \quad \text { if } q>0 .\end{array}\right.$

Here $\ell=\ell_{0} \frac{T}{T_{0}}$ is the width of the kinetic zone.

Using (1) and (3), we can present the equation of charging of a particle in the form

$$
\begin{aligned}
& \frac{d q}{d t}=S A_{0} F(q) T^{2} \exp \left(-\frac{A_{1}-\Delta A_{1}}{k T}\right)- \\
& -S A_{0} T_{f}^{2}\left[1-\frac{\Psi(q)}{\bar{v}_{0_{2}}}\right] \exp \left(-\frac{A_{f}}{k T_{f}}\right) .
\end{aligned}
$$



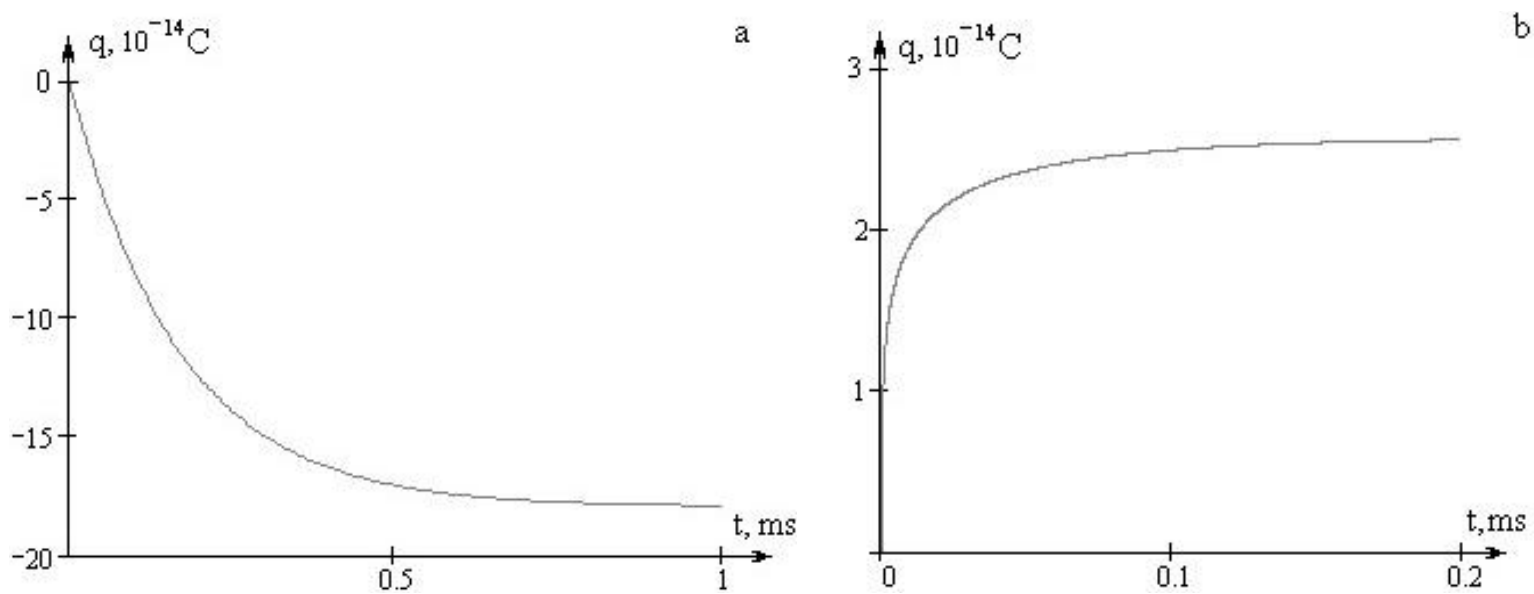

Fig. 1. Time dependences of the charge of particles of $a$ ) copper, at $T_{b}=2100 \mathrm{~K}$, and $\left.b\right)$ tantalum, at $T_{b}=2000 \mathrm{~K} . q_{b}=0 \mathrm{C}, U_{b}=0 \mathrm{~m} / \mathrm{s}$

The time dependence of the particle's temperature is defined by the non-stationary Newton-Richmann law [3] and by Stefan-Boltzmann law

$\frac{1}{3} \operatorname{cor} \frac{d T}{d t}=$

$$
=\left\{\begin{array}{l}
-\alpha\left(T-T_{f}\right)\left(1+\sqrt{\frac{r_{s}^{2}}{\pi a_{g} t}}\right)- \\
-\varepsilon \sigma\left(T^{4}-T_{g}^{4}\right), T \geq T_{f}, \\
-\alpha\left(T-T_{g}\right)\left(1+\sqrt{\frac{r_{s}^{2}}{\pi a_{g} t}}\right)- \\
-\varepsilon \sigma\left(T^{4}-T_{g}^{4}\right), \quad T<T_{f},
\end{array}\right.
$$

$\alpha=\frac{\lambda_{g} N u}{d}, a_{g}=\frac{\lambda_{g}}{c_{g} \rho_{g}}$, where $a_{g}$ is the coefficient of temperature conductivity of the gas, $T_{g}$ - temperature of the gas. The equation of motion of a falling metallic particle reads

$\frac{d U}{d t}=\left(1-\frac{\rho_{g}}{\rho}\right) g-18 \frac{\rho_{g}}{\rho} \frac{\nu_{g}^{2}}{d^{3}} \operatorname{Re}\left(1+\frac{\operatorname{Re}^{2 / 3}}{6}\right)$,

$U(t=0)=U_{b}, \operatorname{Re}=\frac{U d}{\nu_{g}}, \nu_{g}=a_{g} \operatorname{Pr}$. A change of the temperature of particles of copper and tantalum in air, for the particles surrounded by CDP from $\mathrm{Cu}_{2} \mathrm{O}$ and $\mathrm{Ta}_{2} \mathrm{O}_{5}$, was researched in [1]; work [2] did the same for tungsten and molybdenum particles. The following numbers were used in our calculation with $q_{b}=0 \mathrm{C}, U_{b}$ $=0 \mathrm{~m} / \mathrm{s}, \ell_{0}=2 \times 10^{-7} \mathrm{~m}:$ a) for copper: $r=117 \mu \mathrm{m}$, $A_{1}=5.5 \mathrm{eV}, A_{f}=4.9 \mathrm{eV}, T_{f}=2073 \mathrm{~K}, c=384$ $\mathrm{J} /(\mathrm{kg} \cdot \mathrm{K}), \rho=8217 \mathrm{~kg} / \mathrm{m}^{-3}, \varepsilon=0.15$; b) for tantalum: $r=185 \mu \mathrm{m}, A_{1}=4.13 \mathrm{eV}, A_{f}=4.65 \mathrm{eV}, T_{f}=1743$
$\mathrm{K}, c=140 \mathrm{~J} /(\mathrm{kg} \cdot \mathrm{K}), \rho=16600 \mathrm{~kg} / \mathrm{m}^{-3}, \varepsilon=0.45 . \quad \mathrm{A}$ joint analysis of Eqs. (4) and (5) allows us to establish that the time of setting of the quasistationary value of a negative charge for copper particles with a radius of 117 $\mu \mathrm{m}$ is close to $0.5 \mathrm{~ms}$. For positively charged tantalum particles with a radius of $185 \mu \mathrm{m}$, this time is 5 times shorter. At a decrease of temperature, the time of setting of the charge slightly increases. The temperature of a particle practically doesn't change during this time. This allows one to consider a falling metallic particle as having a quasistationary charge for any time moment. For any time moment, the quasistationary charge in the presence of CDP $\left(T>T_{f}\right)$ can be found from the stationary-state condition (5), using (1) and (2):

$$
q_{T}=\left\{\begin{array}{l}
-\left(\left(\frac{4 \pi \varepsilon_{0} r^{2} k T_{f}}{e L}(1-\right.\right. \\
\left.\left.\left.-\frac{F T^{2}}{T_{f}^{2}} \exp \left(-\frac{A_{1}}{k T}+\frac{A_{f}}{k T_{f}}\right)\right)\right)^{1 / 2}+\frac{r e^{1 / 2}}{2 L}\right)^{2} \\
\text { if } q<0, \quad|q|>\frac{e r^{2}}{4 L^{2}} \\
-\left(\frac{4 \pi \varepsilon_{0} r k T}{e^{3 / 2}} \ln \left(\frac{T_{f}^{2}}{F T^{2}} \exp \left(-\frac{A_{f}}{k T_{f}}+\frac{A_{1}}{k T}\right)\right)\right)^{2} \\
\text { if } q<0, \quad|q|<\frac{e r^{2}}{4 L^{2}} \\
\frac{4 \pi \varepsilon_{0} r k T}{e} \ln \left(\frac{F T^{2}}{T_{f}^{2}} \exp \left(-\frac{A_{1}}{k T}+\frac{A_{f}}{k T_{f}}\right)\right) \\
\text { if } q>0 .
\end{array}\right.
$$

In Fig. 2, the time dependences of the temperature and charge for copper particles are shown, just as a sample. As a result of the cooling of a falling particle, its 

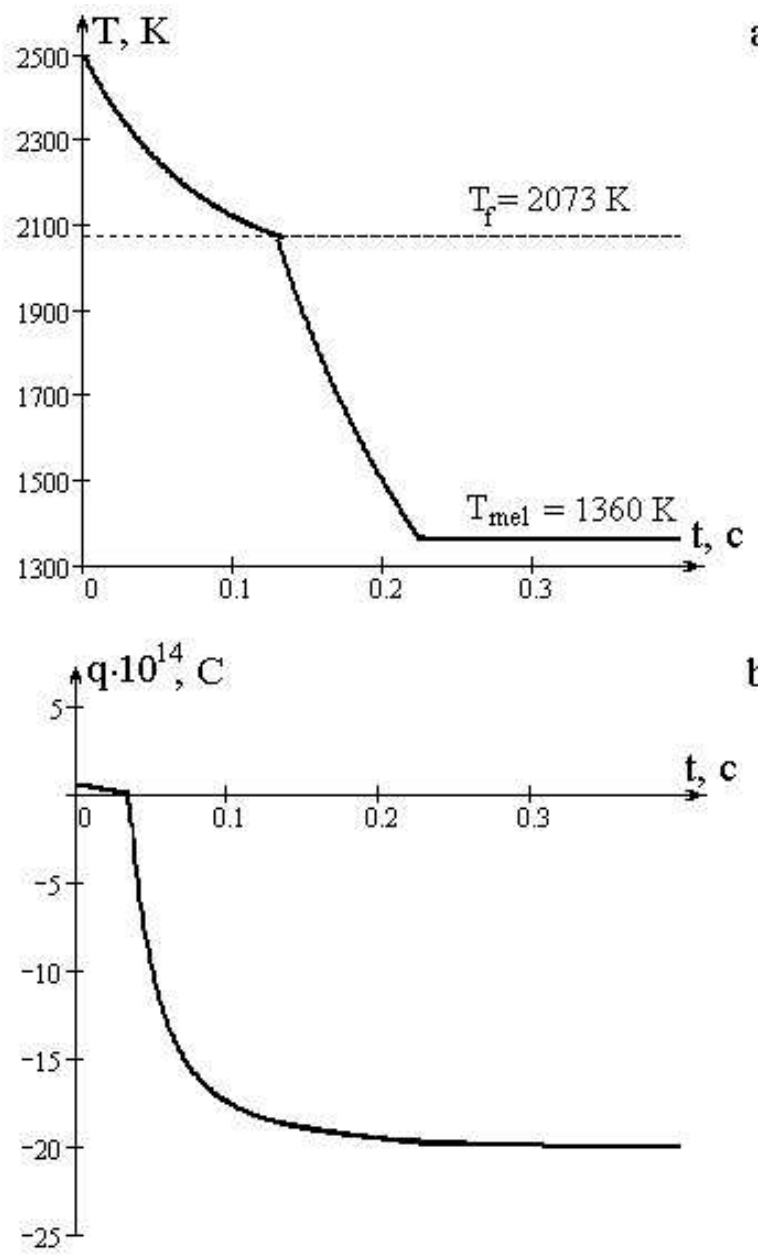

Fig. 2. Time dependences for the temperature and the charge for copper particles, at $T_{b}=2500 \mathrm{~K}, q_{b}=0 \mathrm{C}, U_{b}=0 \mathrm{~m} / \mathrm{s}$. $T_{\text {mel }}-$ melting temperature of a copper particle

temperature decreases to the CDP particles' temperature, and a decrease of the speed of change of the quasistationary charge of a particle with time can be observed. The reason for this is the creation of some CDP particles right on the surface of the metallic particle and a decrease of their temperature [4].

The calculated results were compared with the results obtained in experimental measurements of the temperature and the charge of particles of copper, tantalum, tungsten, and molybdenum. The methodology and results of such measurements are described in [2]. The cause of the ignition (rapid changes in brightness) has been credibly established for copper particles. The dependence of the brightness temperature of copper particle on the time of their motion in air under normal conditions is presented in Fig. 3, considering that the ignition

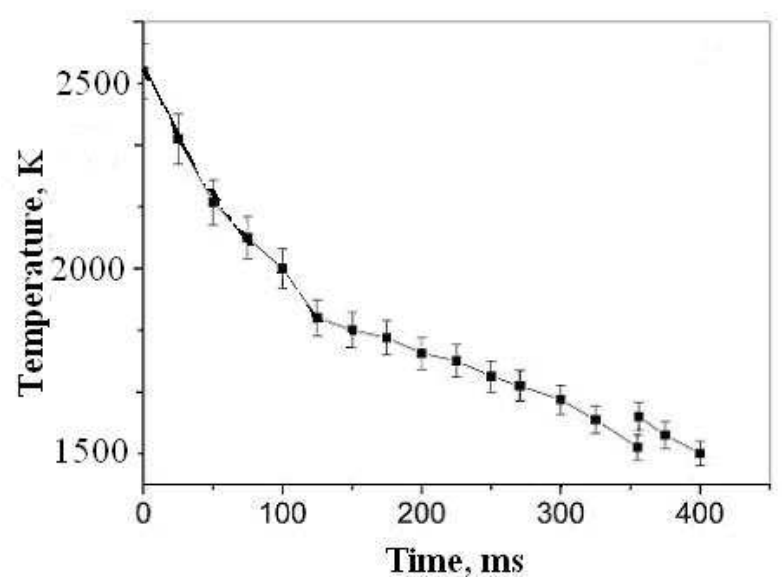

Fig. 3. Time dependences for the temperature and the charge for copper particles, at $T_{b}=2500 \mathrm{~K}, q_{b}=0 \mathrm{C}, U_{b}=0 \mathrm{~m} / \mathrm{s}$. Dotted line - particle temperature is equal to $T_{f}$
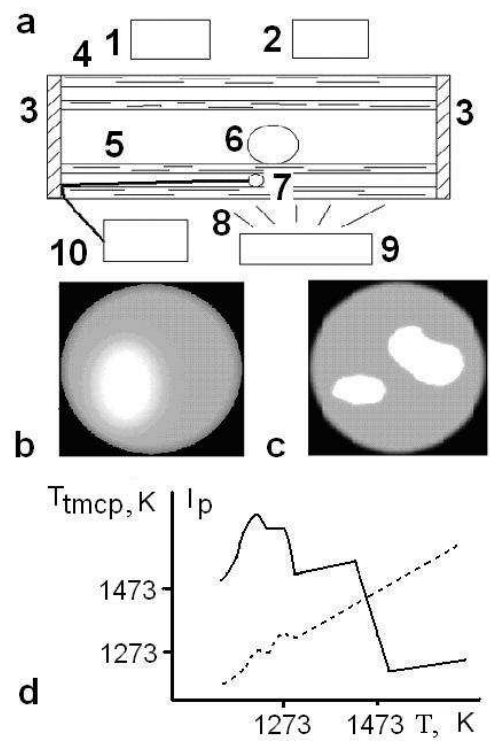

Fig. 4. Basic diagram (a) of the experimental device to study the nature of flashes of a copper particle: 1 - quasimonochromatic pyrometer; 2 - microscope; 3 - cap; 4, 5 - quartz tubes; 6 particle; 7 - thermocouple; 8 - flame from a gas burner $9 ; 10$ - voltmeter. The photos of a particle in the device are made at $T=1373 \mathrm{~K}(b)$ and $T=1515 \mathrm{~K}(\mathrm{c})$. Indications of a thermocouple ( $T_{\mathrm{tmcpl}}-$ the dashed line) and the pyrometer $\left(I_{p}-\right.$ the solid line) depend on the flame temperature

at a time of motion of $270 \mathrm{~ms}$ is caused by a change of the emissivity coefficient of the particle surface. The device (Fig. 4), which allows the controlled heating and cooling of a particle at the simultaneous determination of its monochromatic brightness, was constructed 
for the experimental verification of the concept. Copper particles and a thermocouple located nearby were separated by a quartz tube (to prevent the interaction of the thermocouple material with a particle) and were placed into another quartz tube of larger diameter, which was closed by caps on both ends of it. The tube with a particle could be heated up by a gas burner. The temperature of the particle was consistent to some extent with the temperature of the junction of a thermocouple, whose electromotive force was measured by a voltmeter. The luminosity of a particle was controlled by a brightness pyrometer (with a glass filter with a bandwidth of $0.65 \mu \mathrm{m}$ ). After the sedimentation (with or without flashes), the copper particle was placed into a quartz tube near a thermocouple. After the purging with argon, the tube was closed and heated up to the desired temperature, and the rate of tube's entry into the flame determined the speed of heating of the particle. At the heating of the copper particle which moved with a flash, the pyrometer marked an increase of the luminosity at a temperature of about $1500 \mathrm{~K}$, and the processes of disintegration and dissolution of the surface layer of copper oxide could be visually seen. At the slow cooling, the sequence was inverted: some separate "islands" appeared on the surface of liquid copper, then they grew up while drifting on the surface, merged, and finally formed a solid uneven crust, see Fig. 4,c. There was no increase of the temperature in this case, see Fig. 4, $d$. At the further cooling at a temperature of about $1300 \mathrm{~K}$, another flash happened. There was no changes of the luminosity observed at the point, where the particle was attached to the wall of a quartz tube at a temperature of $1500 \mathrm{~K}$. While the second flash occurred at $1300 \mathrm{~K}$, the luminosity of the attachment point increased, and the thermocouple recorded an increase of the particle temperature, see Fig. 4,d. There was no observed change of the luminosity for particles with a sufficiently small time of sedimentation. With increase in the time of sedimentation on the particles, at a similar study of them, the increasingly significant oxide layer appeared, but the second flash occurred only after a certain time of sedimentation. Finally, when the particle was artificially additionally oxidized in air (by heating up to $1300 \mathrm{~K}$ for one minute) to the nearly complete oxidation of copper, the luminosity change at $1500 \mathrm{~K}$ was not observed; at a temperature of $1300 \mathrm{~K}$, the flash persisted. When a drop of oxide is smeared into a layer (by shaking the tube), the flash at $1300 \mathrm{~K}$ also retains, and the reaction originates in one or two places and then propagates radially throughout the entire sample. The reaction rate also depended on the cooling rate, and,

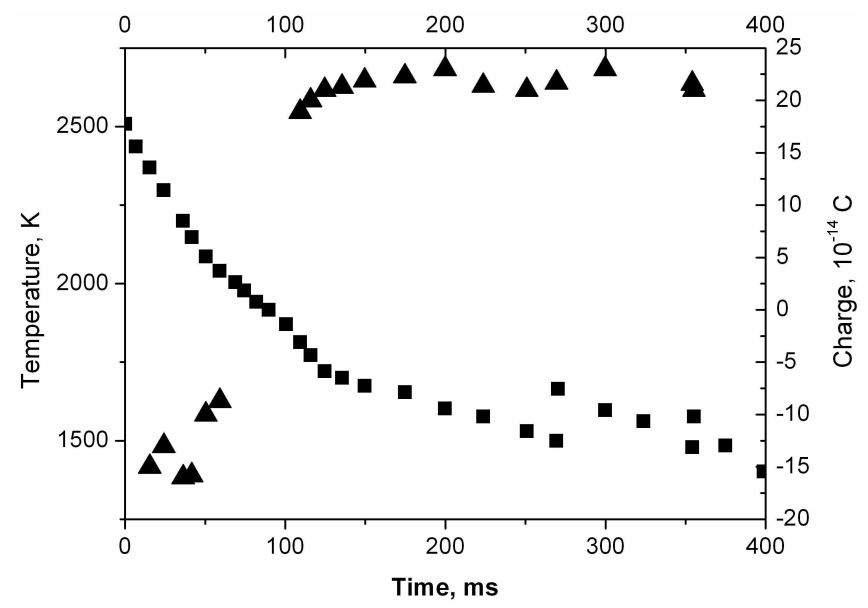

Fig. 5. Experimental dependences for the temperature and the charge for copper particles

at some duration of the cooling, the flash did not appear.

Thus, a sharp change in the luminosity of a copper particle in the process of sedimentation at $1500 \mathrm{~K}$ is related to a change in the emissivity of the particle surface (and, although in a much less degree, to a very little change of the diameter - as the formed oxide density is less than that of copper). At a temperature of about $1300 \mathrm{~K}$, the chemical reaction of oxidation of $\mathrm{Cu}_{2} \mathrm{O}$ to $\mathrm{CuO}$ takes place. Air nitrogen is poorly soluble in copper, while a copper azide decomposes at $600 \mathrm{~K}$, and so the interaction with nitrogen of air was not taken into account. The experimental technique to measure the charge is described in [2] in detail.

The dependences of changes of the charge and the brightness temperature on the time of motion of copper particles are shown in Fig. 5. It is seen that the CDP touch temperature and the temperature, at which the chemical composition of the particle surface is changed (and, therefore, the work function), are synchronized with a change of the charge of a particle (about $70 \mathrm{~ms}$ ). This confirms the calculation scheme in a qualitative aspect.

On the other hand, the calculated mode of change of the charge is not supported by experimental results, and only the order of magnitude is predicted. This may be due to the uncertainty of the choice of tabular data on the work function from the surface of liquid copper and its solutions with oxygen and to the inaccuracy of determination of the distance to the area of formation of $\mathrm{CDP}$ - due to the fact that the temperature dependences of thermophysical characteristics of air were not taken 
into account in the calculation, as well as some other factors of influence.

1. L.A. Lyalin, K.I. Semenov, V.V. Kalinchak, and N.Kh. Kopyt, Ukr. Jour. of Phys. 50, 157 (2005).

2. K.I. Semenov, L.A. Lyalin, V.V. Kalinchak, N.Kh. Kopyt, and A.S. Chernenko, Ukr. J. Phys. 53, 1073 (2008).

3. K.A. Avdeev, F.S. Florov, and S.M. Florov, Khim. Fiz. No. 11, 17 (2006).

4. L.A. Lyalin, K.I. Semenov, V.V. Kalinchak, A.I. Shvets, and N.Kh. Kopyt, Fiz. Aerodisp. Sist. 46, 150 (2009).

Received 22.11.10
ТЕПЛООБМІН І ЗАРЯД МЕТАЛЕВОЇ ЧАСТИНКИ,

ЯКА ОТОЧЕНА КОНДЕНСОВАНОЮ ДИСПЕРСНОЮ ФАЗОЮ ЇЇ ОКИСЛУ

А.С. Черненко, К.І. Семенов, Л.А. Лялін,

В.В. Калінчак, А.В. Мандель

$\mathrm{P}$ е $з$ ю м е

Визначено час встановлення стаціонарного заряду заздалегідь нагрітих частинок міді і танталу вище за температуру плавлення в результаті електрообміну з конденсованою дисперсною фазою свого оксиду. Показано, що в результаті нестаціонарного теплообміну з навколишнім середовищем у будь-який момент часу падіння металеву частинку можна розглядати з квазістаціонарним зарядом. Наведено експериментальні дані по вимірюванню заряду частинок міді і особливостей їі охолодження. 